\title{
Derechos humanos y justicia social: El papel de la sociedad civil
}

\author{
MARTHA RODRÍGUEZ CORONEL* y EMILIO MARTÍNEZ NAVARRO*** \\ * (Universitat Jaume I de Castelló) \\ *** (UNIVERSIDAD DE MURCIa)
}

Los estados eran tradicionalmente los encargados de responder del ámbito público y de promover los derechos humanos (Ruggie, 2013); los mercados atendían a la generación de valor económico; y el tercer sector se encargaba de la integración social. Sin embargo, hoy en día esto ha cambiado, ya no es equivalente la responsabilidad pública con la responsabilidad estatal. Aunque los estados siguen siendo los máximos responsables, no son los únicos agentes responsables de esa tarea. Ahora hablamos de una sociedad civil globalizada (García-Marzá, 2013). No en vano, el subtítulo de este monográfico especial de Recerca es «El papel de la sociedad civil».

Como hemos visto en ediciones anteriores de Recerca desde los distintos ámbitos de la vida pública (Donati y Calvo, 2014) se va haciendo evidente la importancia de la sociedad civil, para la construcción y configuración de los modelos sociales y democráticos que queremos. Hablando de miles de millones de personas a nivel global, se puede comprender cuán importantes son entonces las pequeñas iniciativas que van cobrando fuerza. Pequeñas no porque aglutinen a poca gente o porque tengan menos importancia o impacto, sino precisamente en comparación con esa escala global, donde es difícil lograr acciones de gran magnitud, articular gran cantidad de gente, cierto número de actores sociales, coordinarlos, aún cuando compartamos ideales de justicia, dignidad humana, convivencia y sociedad.

Como podremos confirmar en varios trabajos de esta edición, si alguien es y va a ser el protagonista de la transformación de nuestro modelo de sociedad, es la sociedad civil. De allí la importancia de fomentar y promocionar la articulación de la sociedad civil y los valores cívicos, de suerte tal que las organizaciones e instituciones cívicas, vengan imbuidas, empapadas de un sentido de justicia social, en defensa de los derechos humanos. Somos los ciudadanos a quienes nos afecta, a quienes nos impele más directamente este tema, porque somos precisamente todos los ciudadanos los beneficiarios directos, los «destinatarios» últimos de esa justicia social, de esos derechos humanos. 
Es necesario que los agentes de la sociedad civil comprendamos el alcance de la lucha por la justicia social y los derechos humanos. Que se respeten mis derechos humanos no es sólo una cuestión personal, ni se circunscribe al ámbito local; se trata de instituciones cívicas y estructuras democráticas cuya imbricación, hoy por hoy, incide a nivel global (González, 2013). Resultan significativas las iniciativas en las cuales unos ciudadanos velan por los derechos de otros, en contextos o situaciones que no les atañen directamente, y aún de diferentes localidades o países. Varios ejemplos de esa comprensión de la responsabilidad que va más allá de las fronteras y preocupaciones locales las encontraremos en algunos artículos de este monográfico.

Todo eso nos hace pensar en el tema de la gobernanza, y las dificultades y discusiones en torno a la necesidad y viabilidad de gobiernos, instituciones y sistemas jurídicos globales. Por eso, la consideración de quienes reflexionan sobre el tema de la gobernanza apunta a la importancia de la sociedad civil y de las empresas como parte de ésta, como agentes de justicia social (Conill, 2013).

La garantía de que los derechos humanos sean protegidos en todos los lugares del mundo de forma sostenida y congruente depende del desarrollo y consolidación de una sociedad civil plural, autónoma, bien informada, activa (ONU, 2014), cuya ciudadanía sea capaz de generar y participar en acciones concertadas de carácter colectivo y colaborativo con el sector político y empresarial.

Recerca nos da la oportunidad a través de este monográfico de crear un espacio de encuentro para la reflexión crítica sobre sociedad civil en torno al tema de derechos humanos y justicia social. Distintas voces confluyen para sacar a luz estos temas de increíble relevancia académica y actualidad social.

El primer artículo de este monográfico se titula «Derechos humanos y justicia con las personas con diversidad funcional»; en él se trata de responder a la pregunta de en qué consiste un trato justo para las personas con diversidad funcional y se plantea la cuestión del fundamento de los derechos de dichas personas. El autor analiza el sentido normativo de los derechos de la Convención Internacional sobre los Derechos de las Personas con Discapacidad de 2006, tomando como referencia la teoría de la justicia de Axel Honneth, quien ha iluminado con La lucha por el reconocimiento a los movimientos que reivindican los derechos de tales grupos de personas. El trabajo se centra especialmente en la igualdad jurídica de la teoría tripolar de justicia del autor alemán; y cierra con la ética cordial de Adela Cortina, hallando en ella el fundamento de las demandas de justicia reflejadas en la Convención de 2006. Todo esto, comprendiendo siempre a las personas con 
diversidad funcional como sujetos activos de justicia, desde el modelo social de discapacidad; dicho modelo transforma la imagen social de estas personas, enfocando la discapacidad no como una condición de las mismas, sino como un efecto de la sociedad que instaura barreras económicas, sociales, políticas y culturales que marginan o excluyen a estas personas.

En el segundo artículo, «Debilidades dentro de los procesos de mundialización textil y relación con la RSE a través de un análisis delphi: ética o estética», se explicitan los puntos débiles de la RSE frente al caso particular de las grandes empresas del negocio textil. A partir de información de primera mano recabada específicamente para este estudio, los autores realizan un análisis de la situación, entresacando los principales hilos en la trama de la violación de los derechos humanos en la industria textil. Subrayan la corrupción, en sus diversas formas, y las legislaciones nacionales débiles, como dos de las prácticas más nocivas para la consecución de los objetivos de la RSE, y también como las más difíciles de erradicar. Frente a éstas la RSE, o el modo de llevarla a la práctica, aparece como débil o insuficiente. Enfatizan que la globalización y el modelo de mercado vigente, así como el ejercicio empresarial enfocado en la maximización de resultados, son elementos determinantes en la institucionalización de prácticas que violan los derechos humanos. Desde su perspectiva, las acciones de la sociedad civil son relevantes y su empoderamiento requiere la radicalización de las estructuras democráticas, así como la depuración de los modos de gobierno y los sistemas jurídicos. La salvaguarda de los derechos humanos estaría garantizada así más allá de su positivación, si bien ésta es, a todas luces, indispensable. Debido a su extensión, el estudio es presentado de un modo sintético en esta edición. Luego de destacar los puntos neurálgicos de la cuestión, el trabajo cierra con una lista de propuestas de solución que atienden todas las aristas analizadas en la investigación.

«La crítica de Axel Honneth a la dicotomía habermasiana entre sistema y mundo de la vida» es el título del tercer artículo del monográfico. Aquí se expone esa particular crítica, que considera que dicha distinción conlleva un déficit explicativo de la dinámica social y de sus rasgos patológicos. De este déficit se deriva la concepción de dos sistemas autónomos de acción sin conexión entre sí, impidiendo la detección de la conflictividad interna del mundo de la vida, por sus asimetrías en los procesos de interacción comunicativa, ignorando el núcleo auténtico de lo social. Posteriormente presenta la réplica de Habermas a varios autores. Por último se cuestiona tal dicotomía como limitante de las posibilidades de la sociedad civil excluyéndola del poder político y económico, y al hilo de Honneth y profundizando con Cor- 
tina, García-Marzá y Conill, la autora abre la puerta a reconceptualizar el papel y el carácter de la sociedad civil.

En el cuarto artículo, titulado «La pobreza extrema como una violación de los derechos humanos. La respuesta de la justicia global frente a la beneficencia», la autora mira la pobreza extrema y la desigualdad radical en la distribución del poder económico en clave de violaciones de los derechos humanos, y en la perspectiva de una responsabilidad compartida a nivel global, tanto por los gobiernos y empresas como por los ciudadanos. Se orienta en la línea del impulso a la justicia global, a partir de las ideas de Pogge, por contraste con las ideas de solidaridad de Rawls. En este sentido, revisa enfáticamente la importancia del papel que juega la sociedad civil en la lucha ciudadana y la reforma social. Un derecho humano no positivado fácilmente deriva en una mera declaración. Por lo tanto, hay una estrecha relación entre sociedad civil, eficacia de los derechos humanos, el cabal funcionamiento de las instituciones de gobierno, y una importante interacción entre sistema jurídico, gestión gubernamental y sociedad civil. Para la canalización del rol de esta última, resultan determinantes la educación y la mejora de las estructuras democráticas. A ello habrá de atenderse (i) con perspectiva global, de lo contrario las estructuras que generan desigualdades injustas entre países quedan «impunes»; (ii) teniendo en cuenta que la distribución del poder económico es un factor relevante. Los derechos humanos, como imperativos éticos globales, son un logro social e histórico crucial, y constituyen el marco y suelo democrático para impulsar la justicia global: por la vía positiva, orientativa y, enfáticamente, por la acción ciudadana (la ciudadanía como agente de justicia). La autora destaca que el valor de los derechos humanos reside en la defensa de las libertades que les subyacen (enfoque de capacidades de Sen), y en su probada viabilidad y legitimidad, que trasciende las formas locales y las acotaciones epocales.

«Acomodo de la diversidad, reconocimiento y justicia social» es el quinto artículo de esta edición, en el cual se intenta dar una respuesta a la conciliación de la pluralidad y de la cohesión social a través de tres objetivos. El primero es detallar, desde los presupuestos de la ética y la política del reconocimiento, las características del trasfondo común que comparten las propuestas multiculturalistas y las interculturalistas. El segundo es indagar sobre algunos aspectos del multiculturalismo como lo son: las minorías dentro de minorías, el esencialismo y la ausencia de cohesión social, ya que estos aspectos pueden llegar a propiciar situaciones injustas en el proceso de acomodo de la diversidad; en este mismo apartado, la autora expone algunas soluciones que ofrece el interculturalismo para superar dichos aspectos. Y el tercero es la propuesta del concepto de patriotismo cultural como mecanis- 
mo de cohesión social. Su valor se halla en que prescinde de las referencias éticas, religiosas o culturales, demandando de los ciudadanos una adhesión modesta a la ley y al sistema político que posibilita la libertad civil y la generación de una identidad cívica. La autora concluye resaltando el papel crucial que tiene la sociedad civil a la hora de participar en el proceso de conformación del Derecho y en la elección de esa identidad fundada en los principios de seguridad y libertad para todos.

En el último artículo, «Los nuevos despotismos: imaginando el fin de la democracia», el autor trae nuestra atención sobre un fenómeno geopolítico contemporáneo concentrado geográficamente en la región euroasiática. Al analizarlo intenta mostrarnos las razones por las cuales dicho fenómeno debe interpelarnos y se vuelve relevante tomar posición ante él, asumiéndolo como un fenómeno nuevo y no como una versión de fenómenos conocidos. Entre otras cosas, el autor repara en la fuerza económica de la región, en el carácter transfronterizo tanto de los regímenes políticos como de las alianzas estratégicas gubernamentales, empresariales y mixtas; señala también un uso «refinado» de la violencia, el rol que juegan la "clase media» y los medios de comunicación, en la consolidación de estos regímenes despóticos de nuevo cuño, y enfatiza las diferencias entre estos despotismos y los del siglo xx. Cabe destacar algunas características comunes con problemas políticos globales: el tema de la corrupción y la manipulación del sistema jurídico, del estado de derecho y de la ley, es particularmente relevante; el uso y resemantización distorsionada y pervertida de las «formas» y la retórica democrática; la enorme desigualdad en la distribución del poder económico; la concentración del poder entre las relaciones clientelares. Todas estas características atañen directamente a la preocupación por la defensa de los derechos humanos y la justicia social, como salvaguarda de modelos más democráticos. Se hace evidente que la tarea de lograr estructuras e instituciones sociales más justas tendrá una incidencia directa en el derrotero de nuestras sociedades en los próximos años. Los nuevos despotismos sobreviven porque cultivan formas que permiten que sus súbditos sobrevivan.

\section{BIBLIOGRAFÍA}

Conill, J. (2013): «Caminos para una justicia global» en González, E. (ed.) (2013): Ética y gobernanza: un cosmopolitismo para el siglo XXI, Grana$\mathrm{da}$, Comares.

Donati, P. y Calvo, P. (2014): «New Insights into Relational Goods», Recerca. Revista de Pensament i Anàlisi, 14, pp. 7-17. 
García-MarzÁ, D. (2013): «Democracia de doble vía: el no-lugar de la empresa en la sociedad civil», Revista del Clad. Reforma y Democracia, 57, 67-92.

GonZÁLEZ, E. (2013): «De la gobernanza política a la gobernanza cosmopolita» en GonzÁlez, E. (ed.) (2013): Ética y gobernanza: un cosmopolitismo para el siglo XXI, Granada, Comares.

ONU (2014): El espacio de la sociedad civil y el sistema de derechos humanos de las Naciones Unidas, Oficina del Alto Comisionado de las Naciones Unidas para Derechos Humanos.

Ruggie, J. (2013): Just Business: Multinational Corporations and Human Rigths, New York, W.W. Norton and Company. 